\title{
Osteoporosis Risk and Body Mass Index Comparison among Urban and Rural Menopausal Women
}

\author{
Vita Muniarti Tarawan, ${ }^{1}$ Putri Fatima Adnantami, ${ }^{2}$ Putra Habibie Adnantama, ${ }^{2}$ Putra Haqiqie \\ Adnantama $^{2}$ \\ ${ }^{1}$ Department of Physiology, Faculty of Medicine, Universitas Padjadjaran \\ ${ }^{2}$ Faculty of Medicine, Universitas Padjadjaran-Dr. Hasan Sadikin General Hospital
}

\begin{abstract}
Objective: To compare osteoporosis risk factors between urban and rural menopausal women.

Methods: This study applied the causal-comparative analysis to compare osteoporosis risk factors between urban and rural menopausal women. The subjects included in this study were 40 urban and 40 rural menopausal women who were randomly recruited. The respondents' bone mass density was measured using densitometry. This study also examined several aspects, including the respondents' nutritional status (body mass index calculation) and physical fitness $\left(\mathrm{VO}_{2} \max \right)$. The correlation between osteoporosis risk and either nutritional status or physical fitness among urban and rural menopausal women were tested using Chi square correlation analysis.

Results: This study examined several aspects, including age (years) $58.7 \pm 6.1$ (urban) and $58.3 \pm 6.5$ (rural), $\mathrm{p}=0.815$, body mass index $\left(\mathrm{kg} / \mathrm{m}^{2}\right) 23.7 \pm 3.7$ (urban) and $22.7 \pm 3.6$ (rural), $\mathrm{p}=0.221, \mathrm{VO}_{2} \max$ (average) 27 (67.5\%) (urban) and $25(62.5 \%)$ (rural), $\mathrm{p}=0.624$. The respondents diagnosed as suffering from osteoporosis were statistically measured for the: nutritional status (body mass index) (under) urban $0 \%$, rural ( $\mathrm{p}=0.789$ ) $2.5 \%$, body mass index $7.5 \%$ urban, rural $(\mathrm{p}=0.571) 2.5 \%$, physical fitness condition $\left(\mathrm{VO}_{2} \mathrm{max}\right)$ (average) urban $7.5 \%$, rural ( $\mathrm{p}=0.850$ ) $5 \%, \mathrm{VO}_{2}$ max (poor) urban $7.5 \%$, rural $(p=0.880) 5 \%$. Body mass index and bone mass density calculation results described that the nutritional status of urban and rural menopausal women: normal $12(30 \%)$ vs (32.5\%), osteopenia 8 (20\%) vs (15\%), osteoporosis 3 $(7.5 \%)$ vs (2.5), $\mathrm{p}=0.571$.
\end{abstract}

Received:

July 23, 2014

Conclusions: This study shows that there is no significant difference between osteoporosis risk and nutritional status and physical fitness in urban and

Revised: rural menopausal women.

October 11, 2014

Keywords: Nutritional status, osteoporosis level, physical fitness

Accepted:

February 4, 2015

IJIHS. 2015;3(1):14-20

\section{Introduction}

Menopause refers to a natural biological ageing symptom found in elderly women which is characterized by a permanent menstruation cessation due to the loss of ovarian follicle function. Other multiple organ dysfunctions and physical changes in menopausal women inhibit gonadotropin stimulation, leading to osteoporosis and climacterium syndrome. In

\section{Correspondence:}

Vita Muniarti Tarawan, Department of Physiology,

Faculty of Medicine, Universitas Padjadjaran

Jl. Raya Bandung-Sumedang KM 21 Jatinangor

e-mail: vitalubis13@gmail.com elderly women over 79 years, the reduction in steroid hormone production is one of the major factors causing osteoporosis. ${ }^{1}$

Women entering the perimenopausal or postmenopausal periods have to consume sufficient nutrients. The risk for experiencing bone fracture will increase if the nutrition intake is inadequate, indicating low calcium and vitamin D intakes. Flavonoids are bioactive polyphenols found particularly in fruit and vegetables. However, little is known about their roles in bone health in human; some fruits and vegetables contain potassium and magnesium. ${ }^{2}$ The nutrients that are associated with bone mass density (BMD) are beneficial 
to perimenopausal women and elderly men and women. The benefits include preventing bone loss in elderly men. ${ }^{3}$ Other ways to maintain bone health from osteopenia and to enhance bone mass include adequate calcium and vitamin D supplements consumption and regular exercises. ${ }^{3,4}$ Vitamin D supplements reduce osteoporosis risks and enhance bone mass in healthy women; however, it can also create kidney stone risk. ${ }^{3-5}$

This study compares the osteoporosis risk factors between urban and rural menopausal women. Urban women are women who live in cities while rural women live in remote areas. Bone mass density measurements were performed to analyze bone fracture by using densitometry.

Women with osteoporosis and osteopenia should practice regular exercises even if there is only tentative census available on the type and optimal terms for those who are suffering from low BMD or having BMD risk factors, such as poor balance, decreased muscle strength, and diminished agility. ${ }^{6,7}$ The primary efforts to prevent osteoporosis are doing exercises and managing encouragements. ${ }^{7,8}$

Several studies have reported soy food as the type of food that can enhance bone mass and inhibit hypoestrogenic effect. ${ }^{9,10}$ Significant phytoestrogen diet will increase bone mass in postmenopausal women who suffer from osteoporosis. ${ }^{10}$ People recognize a variety of healthy foods, including yellow-green colored vegetables, mushrooms, fish, scallops, and fruits may influence BMD, while tallow, meat and oil have the opposite effect. ${ }^{9-11}$

In order to socialize menopause risk factors, this study aimed to analyze the differences between risk proportion of osteoporosis and the nutritional status as well as the physical activity (physical fitness) in urban and rural menopausal women.

\section{Methods}

This study applied the comparative analysis method which aims to examine osteoporosis risk in relation with nutritional status (i.e. body mass index calculation) and physical activity (physical fitness/ $\mathrm{VO}_{2}$ max) in both urban and rural menopausal women. The respondents who met the inclusion criteria were those who had never been given hormone replacement therapy, have never experienced any accidental bone fracture, and been given artificial menopause treatment.

The Rule of Thumb approach and sampling method are used in this study in order to recruit potential respondents. The number

Table 1 Respondent Characteristics

\begin{tabular}{|c|c|c|c|c|}
\hline \multirow{2}{*}{ Characteristics } & \multicolumn{2}{|c|}{ Respondent } & \multirow{2}{*}{\multicolumn{2}{|c|}{ p Value }} \\
\hline & Urban & Rural & & \\
\hline Age (yrs.) & $58.7(6.1)$ & $58.3(6.5)$ & 0.815 & \\
\hline Weight (kg) & $54.5(9.8)$ & $49.9(8.9)$ & 0.031 & $(\mathrm{~s})$ \\
\hline Height $(\mathrm{cm})$ & $151.4(6.0)$ & $148.0(6.5)$ & 0.020 & $(\mathrm{~s})$ \\
\hline Body mass index $\left(\mathrm{kg} / \mathrm{m}^{2}\right)$ & $23.7(3.7)$ & $22.7(3.6)$ & 0.221 & \\
\hline Systole (mmHg) & $136.0(14.3)$ & $137.2(15.7)$ & 0.710 & \\
\hline Diastole (mmHg) & $82.2(8.9)$ & $90.0(9.3)$ & $<0.001$ & (vs) \\
\hline Pulse (x/minute) & $80.1(7.4)$ & $84.6(8.9)$ & 0.016 & $(\mathrm{~s})$ \\
\hline Menopause age (yrs.) & & & 0.777 & $* *$ \\
\hline 11 & 1 & 2 & & \\
\hline 12 & 9 & 5 & & \\
\hline 13 & 6 & 5 & & \\
\hline 14 & 7 & 7 & & \\
\hline $15+$ & 17 & 21 & & \\
\hline
\end{tabular}

p value calculated based on t-test. $S=$ significant; VS= very significant

$\left.{ }^{*}\right)$ Chi square test 
of respondents recruited was eighty. These respondents were recruited randomly and by considering the Rule of Thumb approach based on three variables, bone mass density, body mass index, and physical fitness $\mathrm{CVO}_{2}$ max). The respondents involved in this study were 40 urban and 40 rural menopausal women. The rural menopausal women who were involved in this study live in Lembang, West Java, Indonesia.

Two types of variables were studied in this study: independent variables (nutritional status and physical fitness) and dependent variables (osteoporosis risk related to the bone mass density test). The respondents bone mass density, nutritional status, and physical fitness were tested. The equipment used to measure the respondents bone mass density includes densitometry, a dual-energy $\mathrm{X}$-ray absorptiometry. The nutritional status of the respondents was measured using body mass index calculation. Then, the respondents' physical fitness was obtained by conducting aerobic trainings and measuring the $\mathrm{VO}_{2}$ max. The respondents $\mathrm{VO}_{2}$ max was measured using the Astrand-Rhyming nomogram. The nomogram was analyzed by using Pearson's chi-squared test to measure the osteoporosis risk proportion toward nutritional status and physical activity (physical fitness) in urban and rural menopausal women and T-test was used to measure the quantitative average data differences using SPSS 13.0. P value of $<0.05$ was considered statistically significant.

Table 2 Other Related Respondent Characteristics

\begin{tabular}{|c|c|c|c|}
\hline \multirow{2}{*}{ Characteristics } & \multicolumn{2}{|c|}{ Respondent } & \multirow{2}{*}{ p Value } \\
\hline & Urban & Rural & \\
\hline Practicing exercises & & & 1.0 \\
\hline Yes & $39(98 \%)$ & $40(10 \%)$ & \\
\hline No & $1(2 \%)$ & - & \\
\hline Consuming vitamins & & & 0.116 \\
\hline Yes & $4(10 \%)$ & - & \\
\hline No & $36(90 \%)$ & $40(10 \%)$ & \\
\hline Consuming milk & & & 0.458 \\
\hline Yes & $10(25 \%)$ & $13(32 \%)$ & \\
\hline No & $30(75 \%)$ & $27(67 \%)$ & \\
\hline $\begin{array}{l}\text { Consuming hormone replacement } \\
\text { medication }\end{array}$ & & & - \\
\hline No & $40(10 \%)$ & $40(10 \%)$ & \\
\hline Suffering from other diseases & & & 0.256 \\
\hline Yes & $14(35 \%)$ & $19(47 \%)$ & \\
\hline No & $26(65 \%)$ & $21(52 \%)$ & \\
\hline Having Bone fracture & & & 0.001 \\
\hline Yes & $17(42 \%)$ & $32(80 \%)$ & \\
\hline No & $23(58 \%)$ & $8(20 \%)$ & \\
\hline Consuming pain reliever medication & & & 1.0 \\
\hline Yes & 0 & $1(2 \%)$ & \\
\hline No & $40(10 \%)$ & 39 (98\%) & \\
\hline
\end{tabular}


Vita Muniarti Tarawan, Putri Fatima Adnantami, et al.

Table 3 Respondent Body Mass Index, Bone Mass Density, and V0 max

\begin{tabular}{lccc}
\hline \multirow{2}{*}{ Variable } & \multicolumn{2}{c}{ Respondent } & p Value \\
\cline { 2 - 3 } Body mass index & Urban & & 0.408 \\
$\quad$ Under & $4(10 \%)$ & $9(23 \%)$ & $20(50 \%)$ \\
Normal & $23(58 \%)$ & $9(22 \%)$ & 0.891 \\
Over & $12(30 \%)$ & $2(5 \%)$ & \\
Obesity & $1(2 \%)$ & $21(53 \%)$ & 0.624 \\
Bone Mass Density & & $17(42 \%)$ & \\
Normal & $21(53 \%)$ & $2(5 \%)$ & \\
Osteopenia & $16(40 \%)$ & $5(12 \%)$ \\
Osteoporosis & $3(7 \%)$ & $2(5 \%)$ & \\
VO max & & $25(63 \%)$ \\
Very good & $2(5 \%)$ & $7(18 \%)$ \\
Good & $2(5 \%)$ & $1(2 \%)$ \\
Average & $27(68 \%)$ & & \\
Poor & $9(22 \%)$ & - & \\
Very poor & & & \\
\hline
\end{tabular}

Table 4 Respondent Body Mass Index and Bone Mass Density (Osteoporosis Risk)

\begin{tabular}{ccccc}
\hline \multirow{2}{*}{$\begin{array}{c}\text { Body Mass } \\
\text { Index }\end{array}$} & Bone Mass Density & \multicolumn{2}{c}{ Respondent } & p Value \\
\cline { 3 - 4 } & & Urban & Rural & 0.786 \\
Under & Normal & $1(2 \%)$ & $2(5 \%)$ & \\
& Osteopenia & $3(7 \%)$ & $5(12 \%)$ & 0.571 \\
Normal & Osteoporosis & - & $1(2 \%)$ & 0.670 \\
& Normal & $12(30 \%)$ & $6(15 \%)$ & \\
Osteopenia & $8(20 \%)$ & $1(2.5 \%)$ & \\
& Osteoporosis & $3(7 \%)$ & $5(10 \%)$ & \\
Obesity & Normal & $7(18 \%)$ & - & \\
& Osteopenia & $5(12 \%)$ & $2(5 \%)$ & \\
& Osteoporosis & - & - & \\
\hline
\end{tabular}




\section{Results}

The respondents who were involved in this study were both urban and rural menopausal women. The respondents were tested for their bone mass density, body mass index, and $\mathrm{VO}_{2}$ max. The respondents were interviewed about their habits of exercise as well as their vitamin, milk, hormone enhancer, and also painkiller consumptions using a questionnaire(Table 1 ).

Urban menopausal women average weight and height calculations were higher than rural menopausal women. The average body mass index did not show any significant relation. On the contrary, the average diastolic blood pressures and pulses were higher among rural menopausal women.

Exercise habit and vitamin, milk, hormone replacement medication, and also painkiller consumptions did not show any statistically significant relation between urban and rural menopausal women (Table 2). The percentage of bone fracture occured in rural menopausal women was higher (80\%) than those who live in urban areas (42\%).

Bone mass density, body mass index, and $\mathrm{VO}_{2}$ max did not present any significant difference between urban and rural menopausal women (Table 3). Urban menopausal women body mass index was higher which was contrast with the rural menopausal women's body mass index whose $\mathrm{VO}_{2}$ max was higher.

Osteoporosis risk, residential geographic location, and body mass index were analyzed to measure the average values. There was no statistically considerable relation, between the osteoporosis risk and body mass index in both urban and rural menopausal women (Table 4).

The respondent body mass index and $\mathrm{VO}_{2}$ max in urban and rural menopausal women is presented (Table 5). Lower body mass index may cause overweight, obesity, and physical weakness (20/24 respondents). However, the respondents who posessed normal body mass index were in average physical fitness $\left(\mathrm{VO}_{2}\right.$ $\max )(31 / 43)$. The respondents' $\mathrm{VO}_{2} \max$ and body mass index relation in both urban and rural menopausal women did not show any

Table 5 Respondent Body Mass Index and $\mathrm{VO}_{2} \max$

\begin{tabular}{ccccc}
\hline \multirow{2}{*}{$\begin{array}{c}\text { Body Mass } \\
\text { Index }\end{array}$} & Vo $_{2}$ max & Urban & Rural & \multirow{2}{*}{ p Value } \\
\cline { 2 - 4 } Under & Very good & - & $1(2 \%)$ & \multirow{2}{*}{ Respondent } \\
& Good & - & - & \\
& Average & $4(10 \%)$ & $8(20 \%)$ & \\
Normal & Poor & - & - & \multirow{2}{*}{0.544} \\
& Very good & $1(2 \%)$ & $3(7 \%)$ & \\
& Good & $1(2 \%)$ & $2(5 \%)$ & \\
Over & Average & $18(45 \%)$ & $13(32 \%)$ & \\
& Poor & $3(7 \%)$ & $2(5 \%)$ & \\
& Very good & $1(2 \%)$ & $2(5 \%)$ & \\
& Good & $1(2 \%)$ & - & \\
Obesity & Average & $5(12 \%)$ & $4(10 \%)$ & \\
& Poor & $5(12 \%)$ & $3(7 \%)$ & \\
& Very good & - & - & \\
& Good & - & - & \\
& Average & - & - & \\
& Poor & $1(2 \%)$ & $2(5 \%)$ & \\
\hline
\end{tabular}


Vita Muniarti Tarawan, Putri Fatima Adnantami, et al.

Table 6 Respondent $\mathrm{VO}_{2}$ max, Osteoporosis Risk, and Residential Geographic Location

\begin{tabular}{|c|c|c|c|c|}
\hline \multirow{2}{*}{$\mathrm{VO}_{2} \max$} & \multirow{2}{*}{ Bone Mass Density } & \multicolumn{2}{|c|}{ Respondent } & \multirow{2}{*}{ p Value } \\
\hline & & Urban & Rural & \\
\hline \multirow[t]{3}{*}{ Very good } & Normal & $1(2 \%)$ & $4(10 \%)$ & 1.0 \\
\hline & Osteopenia & $1(2 \%)$ & $1(2 \%)$ & \\
\hline & Osteoporosis & $0(0 \%)$ & $0(0 \%)$ & \\
\hline \multirow[t]{3}{*}{ Good } & Normal & $1(2 \%)$ & $1(2 \%)$ & 1.0 \\
\hline & Osteopenia & $1(2 \%)$ & $1(2 \%)$ & \\
\hline & Osteoporosis & $0(0 \%)$ & $0(0 \%)$ & \\
\hline \multirow[t]{3}{*}{ Average } & Normal & $14(35 \%)$ & $12(30 \%)$ & 0.850 \\
\hline & Osteopenia & $10(25 \%)$ & $11(27 \%)$ & \\
\hline & Osteoporosis & $3(7 \%)$ & $2(5 \%)$ & \\
\hline \multirow[t]{3}{*}{ Very-good+good+average } & Normal & $16(40 \%)$ & $17(42 \%)$ & 0.880 \\
\hline & Osteopenia & $12(30 \%)$ & $13(32 \%)$ & \\
\hline & Osteoporosis & $3(7 \%)$ & $2(5 \%)$ & \\
\hline \multirow[t]{3}{*}{ Poor+very-poor } & Normal & $5(12 \%)$ & $4(10 \%)$ & 1.0 \\
\hline & Osteopenia & $4(10 \%)$ & $4(10 \%)$ & \\
\hline & Osteoporosis & $0(0 \%)$ & $0(0 \%)$ & \\
\hline
\end{tabular}

significant value $(p>0.05)$.

Respondent physical fitness, osteoporosis risk, and residence are presented (Table 6). The osteoporosis risk and physical fitness of the respondents did not show any significant value $(\mathrm{p}>0.05)$.

\section{Discussion}

This study is a correlational analysis study to assess the correlation between osteoporosis risk proportion and nutritional status and also the physical fitness. There was no significant correlation found between the osteoporosis risk and nutritional status in rural menopausal woman because they drink adequate amount of milk. In contrary, the nutritional status in urban menopausal women was better because they consume healthy foods and drink milk.

In elderly women whose age are over 50 years, the ability of the intestinal wall to absorb calcium is weaker. This decrease in calcium absorptive ability will lead to low calcium level in blood creating a negative calcium balance. Maintaining the normal calcium level is very important to maintain celullar activity. The loss of bone mass phase in elderly woman is a natural ageing process. The decreased renal calcium reabsorption and intestinal calcium absorption enhance the excretion of calcium in urine. ${ }^{1}$

In this study, the correlation between the risk for osteoporosis and the physical fitness was analyzed (Table 6). The rural menopausal women spend more time in farmlands as their routine physical activities. Meanwhile, urban menopausal women only do daily houseworks, such as washing dishes, sweeping, cooking, and exercising. The data determine that the urban and rural menopausal women physical activities are at the same level; therefore, it is expected that their physical fitness is not significantly different.

There was no significant relation between osteoporosis risk and body mass index in both urban and rural menopausal women. There was also insignificant relation between osteoporosis risk and physical fitness $\left(\mathrm{VO}_{2}\right.$ max) in both urban and rural menopausal women. 


\section{References}

1. Speroff L, Glass RH, Kase NG. Menopause and the perimenopausal transition in clinical gynecologic endocrinology and infertily. $6^{\text {th }}$ ed. London: Lipincott William \& Wilkins; 1999. p. 643-724.

2. Hardcastle AC, Aucott L, Reid DM, Macdonald HM. Associations between dietary flavonoid intakes and bone health in a Scottish population. J Bone Miner Res. 2011;26(5):941-7.

3. Macdonald HM, New SA, Golden MHN, Campbell MK, Reid DM. Nutritional associations with bone loss during the menopausal transition: evidence of a beneficial effect of calcium, alcohol, and fruit and vegetable nutrients and of a detrimental effect of fatty acids. Am J Clin Nutr. 2004;79:155-65.

4. Engelke K, Kemmler W, Lauber D, Beeskow C, Pintag R, Kalender WA. Exercise maintains bone density at spine and hip EFOPS: a 3-year longitudinal study in early postmenopausal women. Osteoporos Int. 2006;17(1):133-42.

5. Ishikawa S, Kim Y, Kang M, Morgan DW. Effect of weight-bearing exercise on bone health in girls: a meta-analysis. Sports Med. 2013;43(9):87592.

6. Wayne PM, Kiel DP, Krebs DE, Davis RB, Savetsky-German J, Connelly $\mathrm{M}$, et al. The Effects of tai chi on bone mineral density in postmenopausal women: a systematic review.
Arch Phys Med Rehabil. 2007;88(5):673-80.

7. Mayoux-Benhamou MA, Roux C, Perraud A, Fermanian J, Rahali-Kachlouf $H$, Revel $M$. Predictors of compliance with a home-based exercise program added to usual medical care in preventing postmenopausal osteoporosis: an 18-month prospective study. Osteoporos Int. 2005;16(3):325-31.

8. Jackson RD, LaCroix AZ, Gass M, Wallace RB, Robbins J, Lewis CE, et al. Calcium plus vitamin D supplementation and the risk of fractures. N Engl J Med 2006;354(7):669-83.

9. Wu X, Cai H, Gao YT, Dai Q Li H, Cai Q, et al. Correlations of urinary phytoestrogen excretion with lifestyle factors and dietary intakes among middle-aged and elderly Chinese women. Int J Mol Epidemiol Genet. 2012;3(1):18-29.

10. Setchell KD, Lydeking-Olsen E. Dietary phytoestrogens and their effect on bone: evidence from in vitro and in vivo human observational and dietary intervention studies. Am J Clin Nutr. 2003;78(3 Suppl):S593-609.

11. Okubo H, Sasaki S, Horiguchi H, Oguma E, Miyamoto K, Hosoi Y, et al. Dietary patterns associated with bone mineral density in premenopausal Japanese farmwomen. Am J Clin Nutr. 2006;83(5):1185-92. 